\title{
INTRODUÇÃO ÀS POLÍTICAS PÚBLICAS: RELATOS DE EXPERIÊNCIA SOBRE UM CURSO DE EXTENSÃO
}

\author{
Viviane Vidal Pereira dos Santos ${ }^{1}$ \\ Maria Tarcisa Silva Bega ${ }^{2}$ \\ Eder Augusto Retka Costa ${ }^{3}$ \\ Barbara Ribas Maciel ${ }^{4}$ \\ Valentina Françóia Loss ${ }^{5}$ \\ Mariane Brantes ${ }^{6}$ \\ Ariely Trindade Gomes ${ }^{7}$ \\ Jonas Palmares $^{8}$
}

Resumo: Este artigo tem como objetivo relatar a experiência do curso de extensão "Políticas Públicas: Uma introdução ao tema" ofertado pelo Programa de Desenvolvimento Urbano e Regional (PDUR), junto ao Grupo de Pesquisa Sociologia e Políticas Sociais, ambos vinculados ao Departamento de Sociologia e ao Programa de Pós-Graduação em Sociologia da Universidade Federal do Paraná. $\mathrm{O}$ curso de extensão atendeu a comunidade acadêmica e agentes públicos e sociais externos à Universidade, mas que lidam com o tema das políticas públicas, seja como tema de estudo ou na prática profissional, bem como em movimentos sociais. Tal relato tem como base a avaliação feita pelos alunos do curso, concluintes ou não, por meio de um formulário eletrônico respondido ao final do mesmo. Esta avaliação possibilitou uma reflexão sobre a experiência da extensão universitária, além de proposições e ajustes para uma futura segunda edição do curso. Foi possível, também, concluir que o curso contribuiu em grande medida para a formação acadêmica de alunos de graduação e pósgraduação da UFPR e de outras instituições, para a prática profissional de servidores da UFPR e de agentes públicos e sociais da comunidade externa, e, por fim, para a compreensão das políticas públicas em geral e seu papel em diferentes contextos políticos e econômicos da sociedade brasileira.

Palavras-chave: Políticas Públicas; Extensão Universitária; Avaliação.

Abstract: This article aims to report the experience of the extension course "Public Policies: An Introduction to the Topic" offered by the Urban and Regional Development Program (PDUR), along with the Research Group Sociology and Social Policies, both linked to the Department of Sociology and to the Postgraduate Program in Sociology of the Federal

\footnotetext{
${ }^{1}$ Universidade Federal do Paraná - UFPR

${ }^{2}$ Universidade Federal do Paraná - UFPR

${ }^{3}$ Universidade Federal do Paraná - UFPR

${ }^{4}$ Universidade Federal do Paraná - UFPR

${ }^{5}$ Universidade Federal do Paraná - UFPR

${ }^{6}$ Universidade Federal do Paraná - UFPR

${ }^{7}$ Universidade Federal do Paraná - UFPR

8 Universidade Federal do Paraná - UFPR
} 
University of Paraná. The extension course attended the academic community and the public and social agents external to the University, but those who deal with the subject of public policies, whether as a topic of study or professional practice, as well as in social movements. Such report is based on the evaluation made by the students of the course, concluded or not, through an electronic form answered at the end of the course. This evaluation made a reflection possible on the experience of university extension, besides propositions and adjustments for a future second edition of the course. It was also possible to conclude that the course contributed greatly to the academic training of postgraduate and graduate students of UFPR and other institutions for the professional practice of UFPR officials and public and social agents of the external community, and, finally, for the understanding of public policies in general and their role in different political and economic contexts of Brazilian society.

Keywords: Public Policy; University Extension; Evaluation;

Revista Extensão em Foco, nº 20, Jan./Jul. (2020), p. 54 - 70. 


\section{INTRODUÇÃO}

O Programa de Desenvolvimento Urbano e Regional (PDUR), programa de extensão universitária do eixo "Direitos Humanos e Justiça", foi criado em 2013 a partir de uma parceria entre o Departamento de Sociologia e o Setor Litoral da Universidade Federal do Paraná, envolvendo os cursos de Ciências Sociais, Serviço Social e Informática e Cidadania, visando contribuir com as dimensões investigativas e interventivas referentes à questão urbana e suas múltiplas expressões na realidade local e regional, bem como as redes de relações que se estabelecem junto às políticas públicas setoriais urbanas (habitação, saneamento, mobilidade urbana, meio ambiente e regularização fundiária) e controle social.

Tendo em vista os princípios da extensão universitária ${ }^{9}$, o PDUR pretende adensar as relações entre teoria e prática na formação dos estudantes, dos agentes públicos e da sociedade civil através do empoderamento em direção ao direito à cidade. Neste sentido, o PDUR, junto ao Grupo de Pesquisa Sociologia e Políticas Sociais (vinculado ao CNPq), ofertou o curso de extensão "Políticas Públicas: Uma Introdução ao Tema" no segundo semestre de 2017, tendo como objetivo contribuir na formação acadêmica de alunos de graduação e pós-graduação, e na capacitação profissional dos servidores docentes e técnico-administrativos da Universidade Federal do Paraná, além de agentes públicos e representantes de movimento sociais. Visto que:

\footnotetext{
(...) a extensão universitária é o que permanente e sistematicamente convoca a universidade para o aprofundamento de seu papel como instituição comprometida com a transformação social, que aproxima a produção e a transmissão de conhecimento de seus efetivos destinatários, cuidando de corrigir, nesse processo, as interdições e bloqueios, que fazem com que seja assimétrica e desigual a apropriação social do conhecimento, das ciências, das tecnologias. (DE PAULA, 2013, p.6)
}

Souza (2007) considera, de forma resumida, as políticas públicas como as ações do Estado frente às demandas sociais, sendo instrumentos fundamentais para gestores e agentes públicos e sociais, e é, também, objeto de estudo interdisciplinar. Para Bega e Vasconcelos (2018), não só o Estado, por meio de suas instituições, tem um papel fundamental no processo de planejamento e implementação de políticas públicas, mas, também, a sociedade civil é um

\footnotetext{
${ }^{9}$ São os princípios da extensão universitária definidos no Fórum de Pró-Reitores da Extensão das Universidades Públicas Brasileiras (Forproex): i) a indissociabilidade entre ensino, pesquisa e extensão; ii) a interação dialógica com a sociedade; iii) a inter e a transdisciplinaridade como princípios organizadores das ações de extensão; iv) a busca do maior impacto e da maior eficácia social das ações; v) a afirmação dos compromissos éticos e sociais da universidade. (DE PAULA, 2013)
}

Revista Extensão em Foco, nº 20, Jan./Jul. (2020), p. 54 - 70. 
elemento importante nas relações de forças estabelecidas nas lutas sociais. Salientam, como exemplo, a força da organização popular através dos movimentos sociais de luta por moradia que, na década de 1980, tiveram suas reivindicações incorporadas à Constituição Federal de 1988, criando bases para a Política Nacional de Desenvolvimento Urbano.

Neste sentido, tendo em vista a universidade como lócus privilegiado de produção de conhecimento e pesquisas no campo das políticas públicas, faz-se necessária a disseminação com a comunidade, além de se constituir como um espaço de troca de saberes e experiências com aqueles que vivenciam na prática as lutas pela efetivação de direitos sociais, a elaboração, a implementação e o impacto das políticas públicas.

O curso intitulado "Políticas Públicas: Uma Introdução ao Tema" foi ofertado entre agosto e dezembro de 2017, totalizando 44 horas. Foi dividido em 10 aulas/módulos perpassando aspectos teórico-conceituais das políticas públicas, além de casos práticos da experiência brasileira. E um décimo primeiro encontro para avaliação dos alunos sobre o curso. Foram ofertadas 80 vagas, em função da capacidade de lotação da sala disponibilizada. A organização do curso recebeu mais de 130 inscrições, formando uma lista de espera para uma eventual segunda oferta. Ao todo, 61 alunos concluíram o curso.

As aulas foram ministradas por professores da UFPR, alunos da pós-graduação e pesquisadores vinculados ao PDUR e ao grupo de pesquisa, além de agentes públicos que lidam cotidianamente com a formulação, implementação e avaliação de políticas públicas.

$\mathrm{Na}$ última aula os alunos foram convidados a avaliar o curso preenchendo um formulário online e participar de uma dinâmica que consistiu em escolher duas palavras que sintetizassem sua experiência e aprendizado no curso. Das palavras escolhidas, criou-se uma nuvem de palavras com a ferramenta digital Mentimeter, como mostra a imagem abaixo:

Revista Extensão em Foco, nº 20, Jan./Jul. (2020), p. 54 - 70. 
Figura 1 - Nuvem de Palavras

Go to www.menti.com and use the code 58682

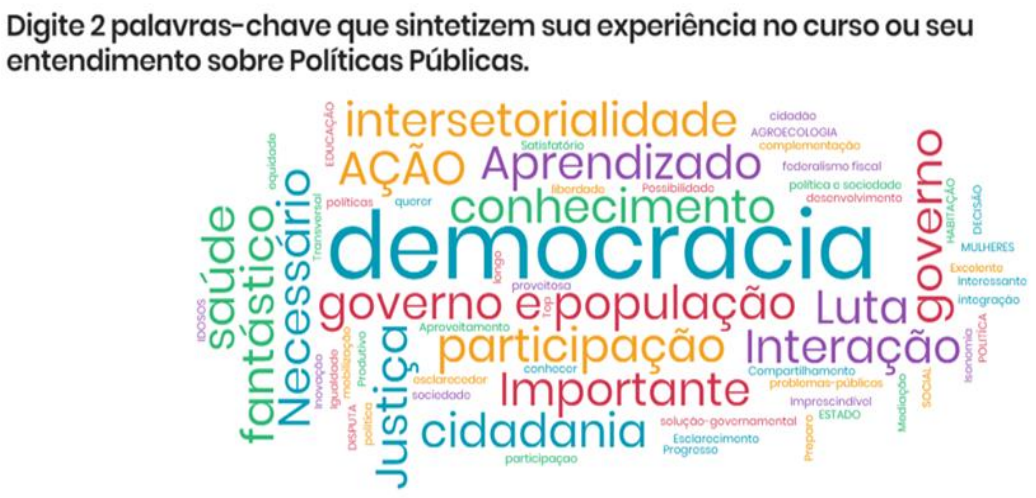

Mentimeter

Digite 2 palavras-chave que sintetizem sua experiência no curso ou seu

Fonte: Os autores (2018).

O resultado da nuvem de palavras motivou a análise mais aprofundada da avaliação feita pelos alunos.

\section{MATERIAIS E MÉTODOS}

A avaliação teve como objetivo colher informações, opiniões e experiências dos alunos em relação ao curso ofertado, tendo em vista a possibilidade de aprimorar aspectos colocados na avaliação para uma segunda edição do curso. Sendo assim, buscou-se colher informações através de um questionário eletrônico da Plataforma Google Docs - Formulário, que foi enviado por e-mail a todos que fizeram a inscrição, concluintes ou não do curso, com questões fechadas e abertas. Como conceitua Cervi (2017), as questões fechadas consistem em perguntas com respostas pré-definidas, já as questões abertas, a partir da pergunta formulada, o entrevistado pode dar sua própria resposta de forma espontânea. As questões foram elaboradas através de parâmetros de avaliação do curso estabelecidas pelos organizadores do mesmo.

O questionário foi elaborado com 11 perguntas e se dividiu em seis partes:

1. Identificação do perfil do respondente: uma questão de múltipla escolha para cada item: vínculo institucional; aluno UFPR; aluno externo; professor UFPR; professor externo; Revista Extensão em Foco, nº 20, Jan./Jul. (2020), p. 54 - 70. 
técnico UFPR; agente público externo; outro. E uma pergunta dicotômica, positiva ou negativa, para saber se o respondente era concluinte ou não do curso.

2. Avaliação das características da oferta e da estrutura do curso: local, dia da semana e horário das aulas, estrutura da sala disponibilizada; por escala linear de 1 a 5, sendo 1=péssimo; 2=ruim; 3=regular; 4=bom; 5=ótimo.

3. Avaliação dos módulos ofertados. Por escala de graduação qualitativa linear de 1 a 5 cada um dos itens abaixo sobre cada módulo: desempenho dos professores; aprofundamento do tema abordado; didática, metodologia e conteúdo; interação com os alunos.

4. Avaliação da contribuição do curso. Uma questão fechada dicotômica, positiva ou negativa, uma questão aberta para que o respondente explicasse de que forma o curso contribuiu em sua formação ou atuação profissional;

5. Identificação dos pontos fortes e pontos fracos do curso em geral; Questão aberta. 6. Críticas e sugestões gerais; Questão aberta.

O uso de questionário de opinião aplicado a um grupo específico de pessoas pode ser caracterizado como survey, onde se coleta informações individuais, as agrega, para se fazer uma conclusão sobre o todo. A parte da elaboração das perguntas é extremamente importante, para que se pergunte apenas o que deseja-se saber.( CERVI, 2017).

Conforme Cervi (2017), os métodos quantitativos incluem técnicas de pesquisa em que sua principal finalidade é a medição de quantidades e quantificação de qualidades. Ou seja, com o método quantitativo é possível identificar regularidades em algum grupo social, padrões gerais e as relações entre eles. Ainda conforme o mesmo autor, é necessário que haja um número mínimo de casos para que a pesquisa seja representativa.

Já o método qualitativo, classifica algumas características do objeto de análise, é usada para medir algo do objeto que já é conhecido. No caso desta pesquisa em específico, o uso de perguntas abertas e fechadas no formulário contribuíram para que se tivesse informações mais precisas e profundas que trouxessem uma melhor avaliação para o curso. "O que determina o predomínio dos métodos a serem utilizados é o objetivo principal da pesquisa e o grau de conhecimento prévio que já exista a respeito”.(CERVI, 2017, p. 11).

De acordo com Quivy e Campenhoudt (2008), a diferença entre os métodos quantitativos e qualitativos é que a informação que baseia a análise numa pesquisa quantitativa seria a frequência com que ela aparece numa base de dados com grande número de informações.

Revista Extensão em Foco, nº 20, Jan./Jul. (2020), p. 54 - 70. 
Sendo assim, neste artigo o método utilizado é o de análise de avaliação, onde procuramos identificar a frequência com que as respostas apareciam no questionário, e delas, inferimos algumas análises. Dessa maneira conseguimos criar um meio de avaliar o curso ofertado pelo programa de extensão.

\section{RESULTADOS E DISCUSSÃO}

\subsection{Identificação do perfil do respondente}

O curso de extensão "Políticas Públicas: Uma Introdução ao Tema" teve a participação de pessoas de várias categorias, sejam de pessoas da universidade ou da comunidade externa à UFPR. No total, foram 53 questionários respondidos. As duas primeiras questões do questionários eram de caráter mais geral, com intuito esboçar quem foram os discentes do curso e quantos o finalizaram. Os números mais representativos do questionário, tirados da primeira questão - "Informe vínculo/ Instituição" - são de alunos da Universidade Federal do Paraná que representam 34\% dos alunos do curso, e dos técnicos da UFPR com 20,8\% do total de respondentes. Dentro do universo externo à Universidade participaram: alunos (17\%), professores $(7,5 \%)$ e agentes públicos de órgãos governamentais (13,2\%). Os demais resultados não foram significativos para identificar a representação das categorias que participaram do curso.

Já na segunda questão, "Você concluiu o curso?", 86,8\% concluíram e 13,2\% não chegaram a finalizá-lo. É possível, com as duas primeiras perguntas do questionário, traçar o perfil daqueles que participam de projetos de extensão na área das políticas públicas e, considerando a dificuldade quase intrínseca de envolver pessoas da comunidade externa à universidade em projetos da UFPR, contar com quase $40 \%$ dos envolvidos de fora da Universidade Federal demonstra como a temática das políticas públicas aproxima e cativa um grande público.

\subsection{Avaliação das características da oferta e da estrutura do curso}

A avaliação da oferta e da estrutura do curso foi feita em quatro perguntas: avalie o horário em que o curso foi ofertado; avalie o dia da semana em que o curso foi ofertado; avalie a localização onde o curso foi ofertado; e avalie a estrutura da sala onde o curso foi ofertado. As opções dadas pelo questionário iam de 1 a 5 , onde 1 era a pior avaliação e 5 a melhor.

Revista Extensão em Foco, nº 20, Jan./Jul. (2020), p. 54 - 70. 
Para a primeira pergunta, sobre o horário ( sexta-feira das $14 \mathrm{~h}$ às $18 \mathrm{~h}$ ) em que o curso foi ofertado, $81,1 \%$ das respostas obtiveram uma avaliação positiva. Na pergunta sobre o dia da semana mais de $50 \%$ das pessoas marcaram a opção "ótimo", seguida pela opção "bom". Ou seja, a maioria das pessoas achou bom o dia em que foi ofertado, sexta-feira, mas 9 pessoas das 53 que responderam, não tiveram essa avaliação tão positiva.

Sobre a avaliação da localização, que foi no Anfiteatro 600, no $6^{\circ}$ andar do prédio Dom Pedro I, do campus da Reitoria, UFPR, 84,9\% das respostas tiveram a avaliação "ótimo", mostrando uma boa avaliação para a localização. Devemos ressaltar também que o módulo sobre a habitação foi ofertado no Prédio da PROGEPE, com uma outra estrutura, então esse número não dá conta dessa mudança.

Já sobre a estrutura da sala ( projetor, cadeiras, etc), esta teve uma avaliação menor do que a localização, mas ainda sim, teve uma boa porcentagem: $85 \%$ dos respondentes colocaram avaliações "ótimo" e "bom" . Contudo, 45,3\% responderam 5 e 39,6\% responderam 4.

De maneira geral, a avaliação foi positiva. Nenhuma das 4 perguntas sobre a estrutura e oferta do curso obteve a resposta "péssimo", onde a maioria das questões obteve resposta "bom" e "ótimo".

\subsection{Avaliação dos módulos ofertados.}

O curso se dividiu em 10 módulos, sendo os cinco primeiros de caráter teórico e conceitual sobre processos de formulação, elaboração, implementação e avaliação de políticas públicas, e os cinco módulos seguintes sobre os casos práticos da experiência brasileira em políticas públicas. Assim sendo, foram ofertados os seguintes módulos:

1: O que são? Como se faz? Quais são?

2 Elaboração de Políticas Públicas: processos de formulação, implementação e avaliação.

3: Controle e Monitoramento social de Políticas Públicas

4: Elaboração de políticas públicas: modelos e casos da experiência brasileira

5: Participação social e cidadania

6: Políticas Públicas no Brasil: o caso da habitação

7: Políticas de saúde e para o envelhecimento

8: Políticas Públicas no Brasil: questões da educação pública no Paraná

9: Novos campos de estudo de Políticas Públicas: Cultura e Gênero

10: Novos campos de estudo de Políticas Públicas: Meio Ambiente e Agroecologia

Revista Extensão em Foco, nº 20, Jan./Jul. (2020), p. 54 - 70. 
Cada módulo foi avaliado individualmente referente aos seguintes quesitos, de livre entendimento dos respondentes sobre cada variável: a) desempenho dos professores; b) aprofundamento do tema abordado; c) didática, metodologia e conteúdo; d) interação com os alunos. Cada um desses quesitos poderiam ser avaliados de 1 a 5 (sendo 1 péssimo e 5 ótimo) ou podia marcar a opção "Não Participei", em caso de ausência no dia em que o módulo foi ministrado.

No primeiro módulo, "Políticas Públicas: O que são? Como se faz? Quais são?”, ministrado pela coordenadora do PDUR, com vasta experiência em pesquisa e docência no ensino superior, a avaliação foi positiva em todos os quesitos, obtendo mais de 70\% de considerações "ótimo". Apenas $3,8 \%$ dos alunos não participaram deste módulo.

Referente ao módulo 2, "Elaboração de Políticas Públicas: processos de formulação, implementação e avaliação", ministrado por um dos pesquisadores do GPSPS, também com vasta experiência na educação superior, percebe-se que a as avaliações continuam positivas, de maneira geral. Mais de 50\% avaliaram o módulo como "ótimo" em todos os quesitos. Somando as avaliações como "bom", mais de $80 \%$ dos respondentes do curso avaliaram este módulo positivamente em todos os quesitos. Importante acrescentar que, dentre os concluintes do curso que responderam ao questionário, este foi o módulo mais assistido com apenas $1,9 \%$ de ausentes. Este professor também ministrou o módulo 4 "Elaboração de políticas públicas: modelos e casos da experiência brasileira", e obteve avaliação similar ao módulo 2, com mais de $80 \%$ de avaliações positivas, mas $18,9 \%$ dos respondentes declararam não terem participado deste módulo.

O módulo 3, "Controle e Monitoramento social de Políticas Públicas”, foi ministrado por um professor de Ciências Sociais do IFPR, também pesquisador do GPSPS e doutorando do Programa de Pós-graduação em Sociologia da UFPR. Este módulo obteve mais de $75 \%$ de avaliações positivas (bom e ótimo), porém aumentou o número de faltas para 9,4\%. Porém, as avaliações "boas" e "regulares" se tornam mais expressivas. Este professor também ministrou o módulo 5, "Participação social e cidadania", que obteve avaliação similar ao módulo 3 em todos os quesitos, assim como os módulos 2 e 4 ministrados pelo mesmo professor. Em geral, esse módulo possibilitou a expansão do conceito de Estado, exemplificado no comentário a seguir:"Foi importante para aprofundar as dimensões do alcance do Estado na vida cotidiana, importante, ainda, para entender o quanto os recursos arrecadados pelo Estado poderiam ser ainda mais abrangentes. Constatar que alguns programas são bons e podem ser ainda melhores. " (Professor Externo)

Revista Extensão em Foco, nº 20, Jan./Jul. (2020), p. 54 - 70. 
A partir do módulo 6, "Políticas Públicas no Brasil: o caso da habitação", iniciaram as discussões das políticas públicas específicas. Os módulos passaram de uma discussão teórica e conceitual para os casos práticos da experiência brasileira, e ministrados, além de professores e pesquisadores do GPSPS, por agentes públicos que lidam com políticas públicas cotidianamente, e alunos da pós-graduação em Sociologia da UFPR que pesquisam na área.

Outra consideração importante é que a partir desta etapa do curso o número de alunos que faltaram as aulas ou que desistiram do curso cresceu. Acredita-se que isto tenha se dado pela longa duração curso, além das aulas serem toda sexta-feira à tarde. Outro fator pode ter sido o fato dos alunos terem maior interesse na parte teórica e conceitual das políticas públicas ou em um tema específico de políticas públicas.

O módulo de habitação contou com técnicos da Companhia de Habitação Popular do Paraná e pesquisadores do GPSPS. As avaliações foram positivas em pouco mais de $50 \%$ das avaliações, mas em média 35\% avaliaram o módulo como "regular" ou "ruim". Os quesitos "didática, metodologia e conteúdo" e " interação com os alunos" tiveram avaliação mais baixa. Neste caso é importante colocar que a aula foi ministrada por agentes com experiência prática em política de habitação e pouco, ou nula, experiência em docência. Vale considerar que no dia em que o módulo foi ofertado houve uma mudança de sala, cuja acústica não contribuia para a interação entre ministrantes e alunos. O percentual de não participantes deste módulo que responderam ao questionário foi de $18,9 \%$.

O módulo 7, "Políticas de saúde e para o envelhecimento", foi ministrado por uma professora da UFPR e pesquisadora vinculada ao GPSPS. Tal módulo apresentou uma avaliação muito similar aos primeiros, mais de 75\% de avaliações "bom" e "ótimo". Algumas considerações foram feitas nas questões abertas sobre a necessidade de mais tempo para aprofundar o tema do envelhecimento. Faltaram a este módulo 22,6\% dos respondentes.

O módulo 8, "Políticas Públicas no Brasil: questões da educação pública no Paraná", foi ministrado por docentes do ensino médio que apresentaram suas questões de pesquisa sobre educação. As avaliações foram similares ao módulo anterior e nas questões abertas também foi colocado que seria necessário mais tempo para discutir e aprofundar o tema. Houve $24,5 \%$ de ausência.

O módulo 9, "Novos campos de estudo de políticas públicas: cultura e gênero", foi dividido em dois. Uma aluna de doutorado do Programa de Pós-graduação em Sociologia da UFPR, vinculada ao GPSPS, ministrou sobre gênero. A parte de cultura ficou a cargo de uma professora do departamento de Sociologia e de outra doutoranda do programa de Sociologia. Revista Extensão em Foco, nº 20, Jan./Jul. (2020), p. 54 - 70. 
Em geral, foi bem avaliado com mais de $70 \%$ de avaliações positivas, com exceção do quesito "aprofundamento do tema abordado", uma vez que, com cada tema teve apenas duas horas para ser abordado. Em relação ao tema "gênero" especificamente, apresentou-se divergências entre os alunos. É válido ressaltar que as diferenças de avaliações se devem ao fato da heterogeneidade da plateia, na qual alguns já possuíam um conhecimento prévio da questão de gênero e outros não. Neste módulo, 18,9\% dos respondentes declararam não ter participado.

Por fim, o módulo 10, "Novos campos em políticas públicas: meio ambiente e agroecologia", foi ministrado por uma professora da UFPR e um doutorando do programa de Sociologia. O módulo também obteve avaliação positiva, mais de $80 \%$. E assim como os módulos anteriores, os respondentes avaliaram nas questões abertas que faltou aprofundar o tema. Nestas questões os alunos também destacaram como ponto positivo a organização do curso colocar o tema do meio ambiente e da agroecologia nas políticas públicas. Este foi o módulo com mais ausências, $37,7 \%$.

\subsection{Avaliação da contribuição do curso}

A questão 8 do questionário foi dividida em duas partes, uma primeira fechada:" 8 . Em geral, o curso contribuiu para sua prática profissional ou para aprofundar temas de interesses de pesquisa?", nessa questão era possível responder "Sim" ou "Não", e uma segunda parte aberta: "8.1 De que forma se deu esta contribuição?”. 53 pessoas responderam a primeira questão do questionário, sendo que 98,1\% responderam "Sim", ou seja, a maior parte dos participantes considerou que o curso lhes foi útil de alguma forma. Quanto à segunda questão, feita de maneira aberta, foram obtidas 52 respostas de participantes das mais variadas formações e com diferentes estágios de familiaridade com o tema das políticas públicas.

\footnotetext{
Me serviu como uma excelente introdução aos aspectos teóricos e práticos relativos às políticas públicas. Como psicólogo, nenhum dos assuntos abordados no curso me eram familiares (nenhum deles é discutido com profundidade durante a graduação). [Agente Público/Comunidade Externa]

Como pretendo cursar o Mestrado em Políticas Públicas - UFPR no ano que vem, o curso me ajudou tanto na construção do meu Projeto de Pesquisa quanto na Prova que fiz para Seleção no Programa. [Comunidade Externa]

O curso foi importante para fazer um panorama geral da evolução das
}

Revista Extensão em Foco, nº 20, Jan./Jul. (2020), p. 54 - 70. 
Políticas Públicas no Brasil e para conhecer a agenda de atuação nos principais setores para PP. [Aluno UFPR]

Depois que comecei o curso de extensão "Introdução às Políticas Públicas", percebi o quanto estava e estou desatualizado, porém com esse curso terei mais possibilidade e argumentos para sugerir novas Políticas, principalmente sociais e ambientais na empresa onde trabalho, e para isso posso utilizar os dados coletados e repassados pelos Professores. Em minha opinião o curso foi excelente, porém devido ao curto espaço de tempo Temas importantes não puderam ser aprofundados, esse seria o único ponto negativo durante esse período do curso. [Agente Público/Comunidade Externa]

Conferiu-me um norte quanto à orientação acadêmica que desejo seguir. [Técnico UFPR]

Participar deste curso me fez ver que no Município onde atuo ainda precisamos desenvolver muitas políticas públicas, como por exemplo, políticas públicas para as mulheres em específico, políticas estas que até participar do curso eu não tinha me atentado para o quanto são relevantes e necessárias. [Aluno da UFPR]

Os depoimentos dos participantes reproduzidos acima evidenciam como o curso contribuiu para os mais diversos propósitos: como para elaboração de projetos para seleções de mestrado, tema para TCC's, atualização de conhecimentos e até mesmo para um primeiro contato com o tema. Baseando-se nas respostas dadas à questão 8 e dos comentários da questão 8.1 concluímos que o curso atingiu os objetivos de proporcionar uma formação inicial contribuindo para a formação acadêmica dos estudantes e também para a prática profissional de agentes públicos, professores da rede estadual de ensino, dentre outros.

\subsection{Identificação dos pontos fortes e pontos fracos do curso em geral}

Na questão 9 o seguinte questionamento foi feito aos participantes: "9. Quais são os pontos fortes e fracos que você identificou no curso?". Através delas nota-se a heterogeneidade dos alunos do curso, que teve como público desde alunos de graduação, técnicos, professores da rede pública, dentre outros. Em função disso as opiniões sobre o conteúdo divergiram: embora alguns comentários apontem que os temas deveriam ter sido abordados com maior profundidade houve quem considerou os conteúdos avançados demais. Muitos participantes elogiaram os temas abarcados pelo curso, sendo que a preparação dos professores foi lembrada em boa parte das respostas como um ponto forte. A organização (parte técnica) bem como o curso ser aberto a vários públicos também foram elogiados:

Revista Extensão em Foco, nº 20, Jan./Jul. (2020), p. 54 - 70. 
Pontos fortes, são a preparação dos professores. Os pontos fracos, abordados alguns temas complexos para os leigos. [Técnico UFPR]

Pontos fortes - Professores qualificados e temas de relevância.

[Professor/Comunidade Externa]

O principal ponto forte do curso ao meu ver foi a abertura aos alunos da graduação, professores, pessoas da comunidade, terceirizados e etc [...] [Aluno UFPR]

fortes: o aporte teórico, a abordagem dos temas, a estrutura do curso, a oferta para participação livre. [...] [Técnico UFPR]

pontos fortes: variedade de temas, localização, equipe bem organizada. Pontos fracos: horário (gostaria que tivesse sido a noite) [Agente Público/Comunidade Externa]

Como ponto forte eu destaco a composição heterogênea dos participantes e a passagem por inúmeros setores de políticas públicas durante o curso. [Estudante/Comunidade Externa]

Quanto aos pontos fracos, a falta de profundidade em alguns temas e a própria falta de tempo para aprofundá-los (dada a proposta e estrutura do curso) foi bastante lembrada, alguns módulos como o de gênero e habitação receberam críticas diretas:

[...]Outro comentário, refiro-me à participação de convidados com muito aprofundamento jurídico para discutir políticas públicas da habitação, implicando em muito tempo para leitura da legislação. No mesmo tema, a participação da profissional da área da arquitetura conseguiu expressar-se com argumentos técnicos da área, mas dentro do interesse da discussão das políticas públicas. [...] [Professor/Comunidade Externa]

[...] Pontos fracos foi a política habitacional (pois não trouxeram as pessoas corretas da COHAPAR que realmente entendem e trabalham com políticas públicas); e a discussão sobre políticas públicas sobre gênero foi muito vaga. [Técnico UFPR]

O horário foi citado em vários comentários como algo negativo e alguns participantes consideraram o curso cansativo:

Forte: participação dos alunos, conhecimento dos professores. Fracos: por ter se abordado um grande número de temas, em alguns casos eles não puderam ser aprofundados da maneira desejada. [Aluno UFPR]

Revista Extensão em Foco, nº 20, Jan./Jul. (2020), p. 54 - 70. 
São temas de relevância e de interesse geral. A questão tempo de duração do curso diminui o aprofundamento dos temas. [Técnico UFPR]

Ponto negativo foi o curto espaço de tempo, com isso Temas importantes não foram aprofundados. [Agente Público/Comunidade Externa]

Forte: organização e planejamento do curso. Fraco: duração das aulas (um pouco longa). [Estudante/Comunidade Externa]

Os pontos fortes foram os professores e o ponto negativo foi a carga horária extensa [Aluno UFPR]

Fortes: conteúdo excelente e preparação dos professores. Fracos: Horário, duração (4 horas seguidas, numa sexta-feira é puxado!) e dia da semana. [Aluno UFPR]

O curso em geral foi bastante elogiado pelo público, com vários participantes colocando que não haviam pontos fracos. O tempo de duração recebeu críticas mas que se dividiram em ser muito longo ou em ser muito curto. A qualidade dos ministrantes foi o maior ponto positivo, sendo apontada por vários dos participantes.

\subsection{Críticas e sugestões gerais}

Em geral, o módulo introdutório do curso de políticas públicas foi recebido e avaliado positivamente pelo público, indicando-o como um bom aparelho para maior aprofundamento bibliográfico e norteador para aqueles que projetam uma especialização acadêmica no campo de políticas públicas.

As duas últimas perguntas do questionário eram abertas, as quais os participantes podiam escrever textos corridos sobre a experiência do curso de extensão. Na questão "Sugira conteúdos, ênfases e aprofundamentos em Políticas Públicas que possam ser trabalhados em uma próxima edição do curso de extensão" obtivemos 39 respostas e alguns pontos destacaramse entre essas. Surgiram especialmente sugestões de temáticas já trabalhadas nos módulos, mas com uma abordagem diferente da que foi proposta, apontando interesses de aprofundamento em políticas públicas nas áreas da saúde, educação e, sobretudo, meio ambiente, citado muitas vezes. Observa-se nesse ponto que os avaliadores que apontam para as questões relativas ao meio ambiente também o fazem para a relevância das políticas públicas voltadas à saúde. Outros temas presentes nas sugestões enfatizaram questões de assistência social e gestão 
pública e por fim, módulos que aprofundem as questões econômicas, tecnologia e ciência, habitação, deficientes e o estatuto do idoso.

Eu gostei muito da proposta do curso e dos assuntos abordados: uma introdução, uma visão de como são introduzidas as políticas públicas no Brasil e depois estudos de caso sobre questões estruturais que mais preocupam a sociedade: saúde, educação, meio ambiente, moradia, etc. Gostei muito dessa maneira. Para um futuro curso eu apenas acredito que seria legal trazer estudos de caso em áreas, ou mesmo novos pesquisadores que pesquisem áreas parecidas às que já foram expostas. [Ex-aluno UFPR].

Sugiro a discussão um tanto mais aprofundada da habitação, englobando a questão do direito à cidade. [Agente público externo].

Aprofundar mais em relação às Políticas de Saúde e do meio ambiente. [Técnico UFPR].

Um tema que eu sugiro seria Saneamento Básico, que além de ser uma questão ambiental está totalmente ligada a saúde pública. [Agente público externo].

O último ponto do questionário, “considerações gerais”, com 36 respostas, serviu para agradecimentos, elogios e parabenizações pela organização e estrutura do curso de extensão. Mesmo que alguns comentários façam críticas pontuais, como por exemplo, a questão da comunicação em que uma participante escreveu: "melhorar a comunicação (e-mail, Facebook), as informações ficavam truncadas ou mal entendidas [...], nem todos os participantes recebiam os e-mail [...]", explicitaram, sobretudo, a iniciativa e a organização promovida pela equipe responsável pelo andamento do curso e propuseram pequenas modificações relacionadas ao horário estendido das aulas, das 14 horas às 18 horas, e a dificuldade de acessar os materiais disponibilizados pelos professores dos módulos, recomendando melhorar a comunicação. Porém, no geral esse espaço recebeu quantitativamente mais elogios à críticas.

O curso foi excelente e de muita importância para enriquecimento dos conhecimentos do assunto de todos os participantes. Todos as pessoas envolvidas estão de parabéns pelo belíssimo curso. [Técnico UFPR].

Também, algumas respostas tinham apelo à análise das políticas públicas no cenário político. Portanto, a inserção desse debate no momento conjuntural foi elogiado e algumas respostas analisaram o período político e o papel - e fragilidades - que as políticas públicas exercem nos diferentes cenários da política brasileira.

\section{CONCLUSÕES}

Revista Extensão em Foco, nº 20, Jan./Jul. (2020), p. 54 - 70. 
De maneira geral, foi possível concluir que o curso contribuiu em grande medida para a formação acadêmica de alunos de graduação e pós-graduação da UFPR e de outras instituições, para a prática profissional de servidores da UFPR e de agentes públicos e sociais da comunidade externa. E contribuiu para a compreensão das políticas públicas em geral e seu papel em diferentes contextos políticos e econômicos da sociedade brasileira.

Alguns aspectos da avaliação merecem uma atenção especial, para que possamos aperfeiçoar o curso em próximas edições.

As duas primeiras perguntas do questionário, que traçam o perfil dos respondentes que participaram do curso, mostram uma grande adesão de pessoas da comunidade externa contando com quase $40 \%$ dos envolvidos de fora da Universidade Federal. Assim tivemos um grupo de alunos bastante heterogêneo, com pessoas tanto de fora quanto de dentro da universidade, o que também resultou em avaliações diversificadas nas questões abertas. Porém esse dado nos mostra, além do número de pessoas que se inscreveram no curso, como que a temática das políticas públicas é atual e aproxima e cativa um grande público. O curso teve um resultado positivo no que diz respeito à extensão, em compartilhar estudos de dentro universidade para pessoas de fora.

A avaliação da estrutura do curso também foi bastante positiva. O horário e dia em que foram ofertados, acredita-se que algumas respostas foram negativas por conta de ser dia de semana de tarde, e muitas pessoas terem que trabalhar nesse horário.

Em geral, os módulos foram bem avaliados, levando em consideração as distintas características de cada aula, com diferentes palestrantes, ora professores universitários, ora alunos de pós-graduação ou agentes públicos, cada qual com bagagens e didática diversas, lidando com um público também diverso.

O curso contribuiu em grande medida para a formação dos alunos e para a prática profissional de agentes públicos. O público diverso, da comunidade acadêmica e, também, atores externos à Universidade, permitiu exercer a extensão universitária a partir da socialização do conhecimento científico.

A oferta do curso serviu, também, de experiência para os alunos voluntários e colaboradores do PDUR, bem como pesquisadores vinculados ao grupo de pesquisa Sociologia e Políticas Sociais, que participaram da organização e puderam vivenciar a extensão universitária, além de lidar com uma rotina diversa a da sala de aula tradicional.

Revista Extensão em Foco, nº 20, Jan./Jul. (2020), p. 54 - 70. 


\section{REFERÊNCIAS}

CERVI, E. U. Surveys para Coleta de Dados Individuais. In: Manual de Métodos Quantitativos para Iniciantes em Ciência Política. Curitiba: CPOP-UFPR, 2017, p. 143170 .

QUIVY, R.; CAMPENHOUDT, L. V. Análise das Informações. In: Manual de Investigação em Ciências Sociais. Lisboa: Grafiva, 2008. p.211-241.

PAUlA, J. A., A Extensão Universitária: História, Conceito e Propostas. In: Interfaces: Revista de Extensão da UFMG. Belo Horizonte. v. 1, n. 1, 2013.

SOUZA, C. Estado da Arte da Pesquisa em Políticas Públicas In: Políticas Públicas no Brasil.(Orgs.) ARRETCHE, M.; HOCHMANN, G.; MARQUES, E. Rio de Janeiro: Editora Fiocruz, 2007, p.65-86.

BEGA, M. T. S.; VASCONCELOS, M. E. A., Limites e possibilidades de investigação e intervenção do Programa de Desenvolvimento Urbano e Regional. In: Intervenções na Cidade: Relatos de experiência de pesquisa-extensão. (Orgs.) BEGA, M. T. S.; VASCONCELOS, M. E. A. Jundiaí: Paco Editorial, 2018, p.19-46. 